\title{
Urbe fágica
}

Ricardo Pozzo ${ }^{1}$

As imagens que compõem esta edição da Revista Interface fazem parte do Projeto Urbe Fágica do fotógrafo Ricardo Pozzo, nascido em Buenos Aires e radicado em Curitiba, Brasil, desde meados do século XX.

\section{URBE FÁGICA}

Projeto fotográfico com base nas teorias de Georg Simmel, Vilém Flusser e Jean Baudrillard, que tenta provocar, em um hipotético observador aleatório, a constatação de que os estímulos provenientes da realidade são, e cada vez mais, excessivos o suficiente para que as contradições sociais costurem o abismo entre o discurso e as práticas cotidianas. Inserido numa realidade pragmática, mergulhado em um oceano absurdo de estímulos e informação, o habitante da urbe, como nos diz Simmel, não possui capacidade psicobiológica suficiente para que surja, em sua consciência, o elo crítico que o faria estacar em sua atividade autômata e perceber as contradições no todo do ciclo social. Identificado pelo discurso midiático maniqueísta, ora como algoz, ora vítima, muitas vezes simultaneamente nas duas posições, o habitante da urbe, psicoburgês, torna-se presa de uma rotina de manutenção da pólis, estando sempre um passo aquém de suas obrigações, ao mesmo tempo em que seus anseios primitivos, negados por uma moral de conduta, são estimulados pela publicidade. Essa dicotomia restringe sua percepção do processo natural em seu entorno, no qual está inserido, deixando então de considerar os caminhos e limites que o impediriam de sobrecarregar o sistema orgânico, permitindo compreender-se como sujeito dentro da extrema fluidez em que ocorrem as experiências vividas em si e em sociedade.

Como Flusser nos convida a perceber, o fotografo é similar a um caçador na tundra ou, no caso do projeto urbe fágica, em busca do instantâneo que, no cotidiano revele as contradições de nosso contrato social.
${ }^{1}$ Rua Miguel Odia Fagundes, 28, Fazendinha. Curitiba, PR, Brasil. 81.320-150 
CRIAÇÃO

Ricardo Pozzo é fotógrafo, filho de fotógrafo, e há oito anos dedica-se ao projeto Urbe Fágica, fotografando em máquinas analógicas, tais como a Nikon FM10 ou Canon EOS Rebel 2000. Trabalha também no registro fotojornalístico de causas sociais, como a Ocupação Nova Primavera-CIC/ Sabará 2012, com 3 fotos nessa edição, e é fotógrafo responsável pelo jornal literário paranaense RelevO, além de ter outras páginas de fotografia.

É escritor, poeta, tradutor, músico, fotógrafo, e produtor cultural. Desde 2011, é curador do projeto Vox Urbe, no Wonka Bar, em Curitiba, um espaço para a percepção poética - aos que se sabem e aos que ainda não se sabem poetas. Membro do Pó e Teias, coletivo literário, é um dos coordenadores do blog, de mesmo nome.

https://twitter.com/RicardoPozzo http://olhares.uol.com.br/elquetzal http://www.cronopios.com.br/site/poesia.asp?id=5556 http://www.curitibacultura.com.br/noticias/entrevistas/o-pozzo-e-a-poesia-na-urbe-0 http://www.mallarmargens.com/2012/09/fotocorpos-por-ricardo-pozzo.html

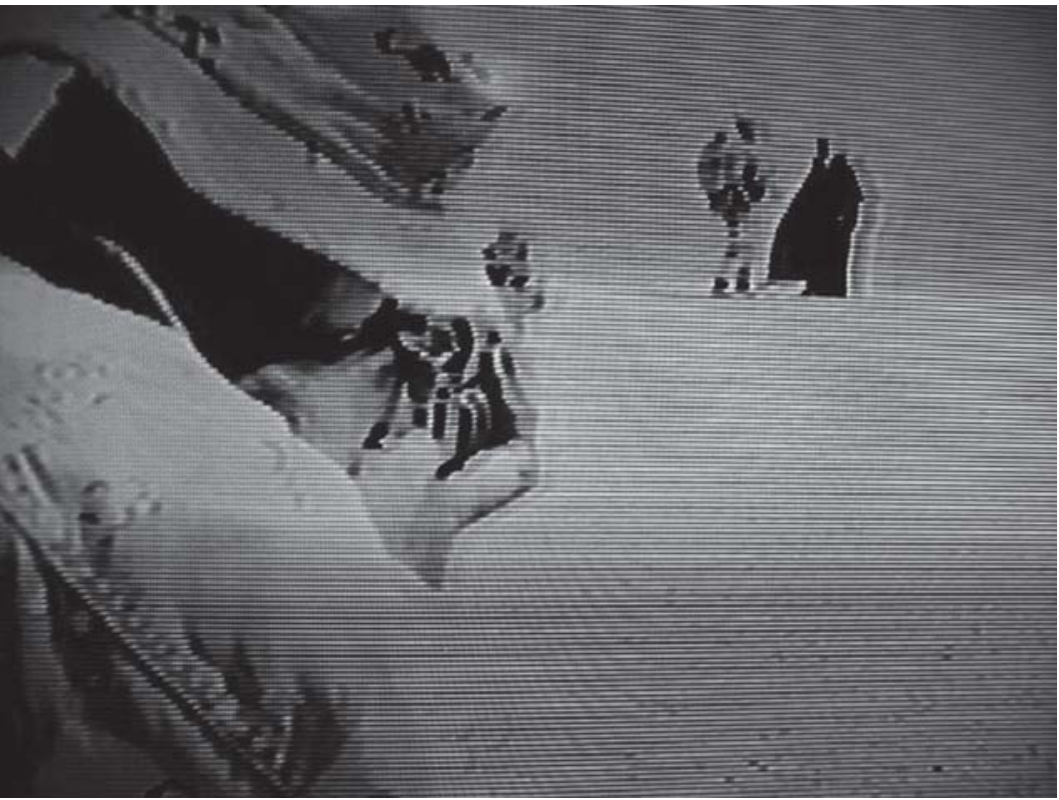




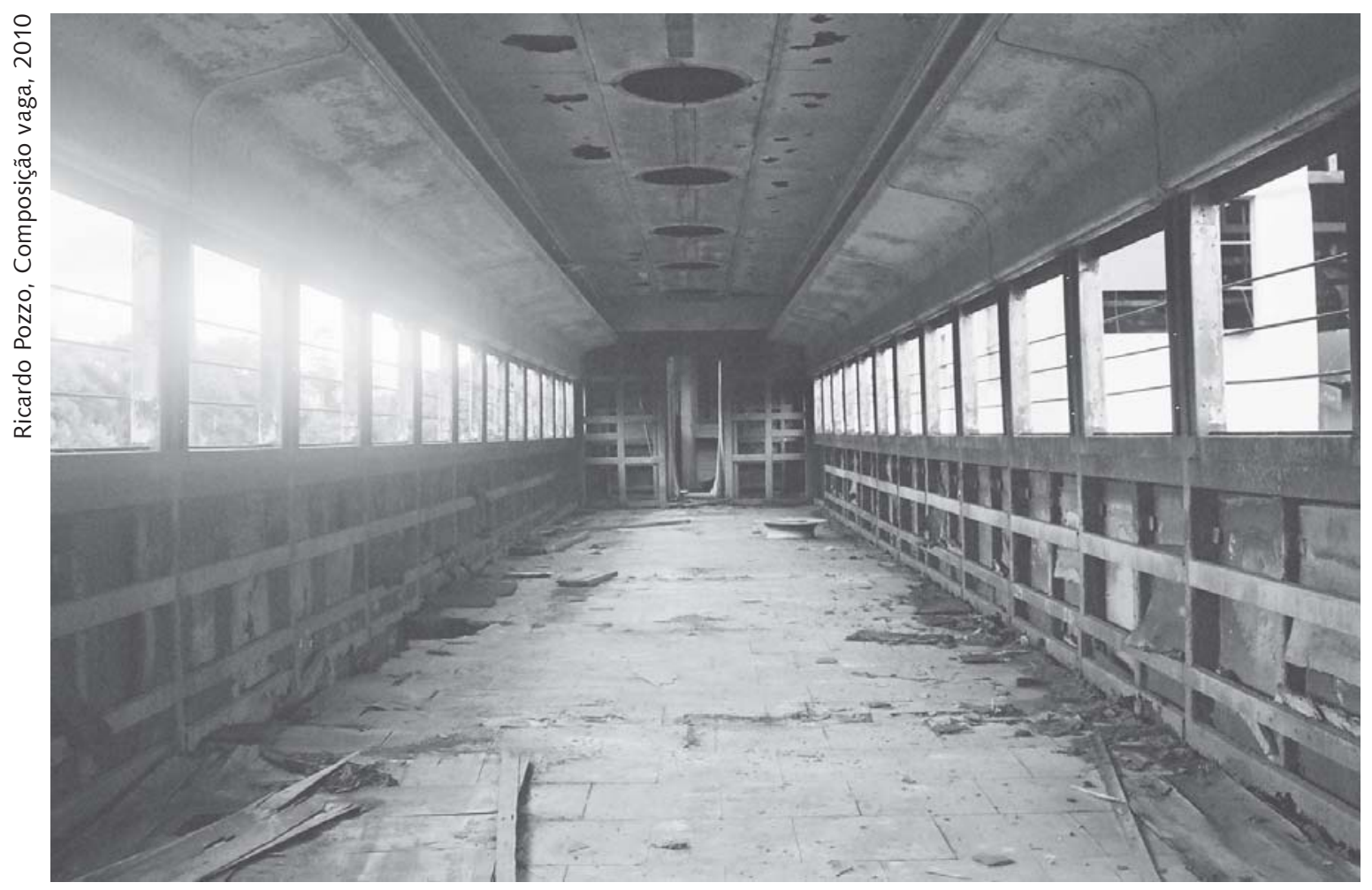

\title{
Urbe[m] Samsara
}

\section{Escatológica cosmogonia a cada quadra}

\section{Urbe[m] Samsara}

que pouco você vê re significada

a cada Cosmo [de]

\author{
subjetividade \\ individualizada!
}

www.poeteias.blogspot.com.br/2012/02/urbem-samsara.htlm 
Ricardo Pozzo, Projeto Urbe fágica, 2011

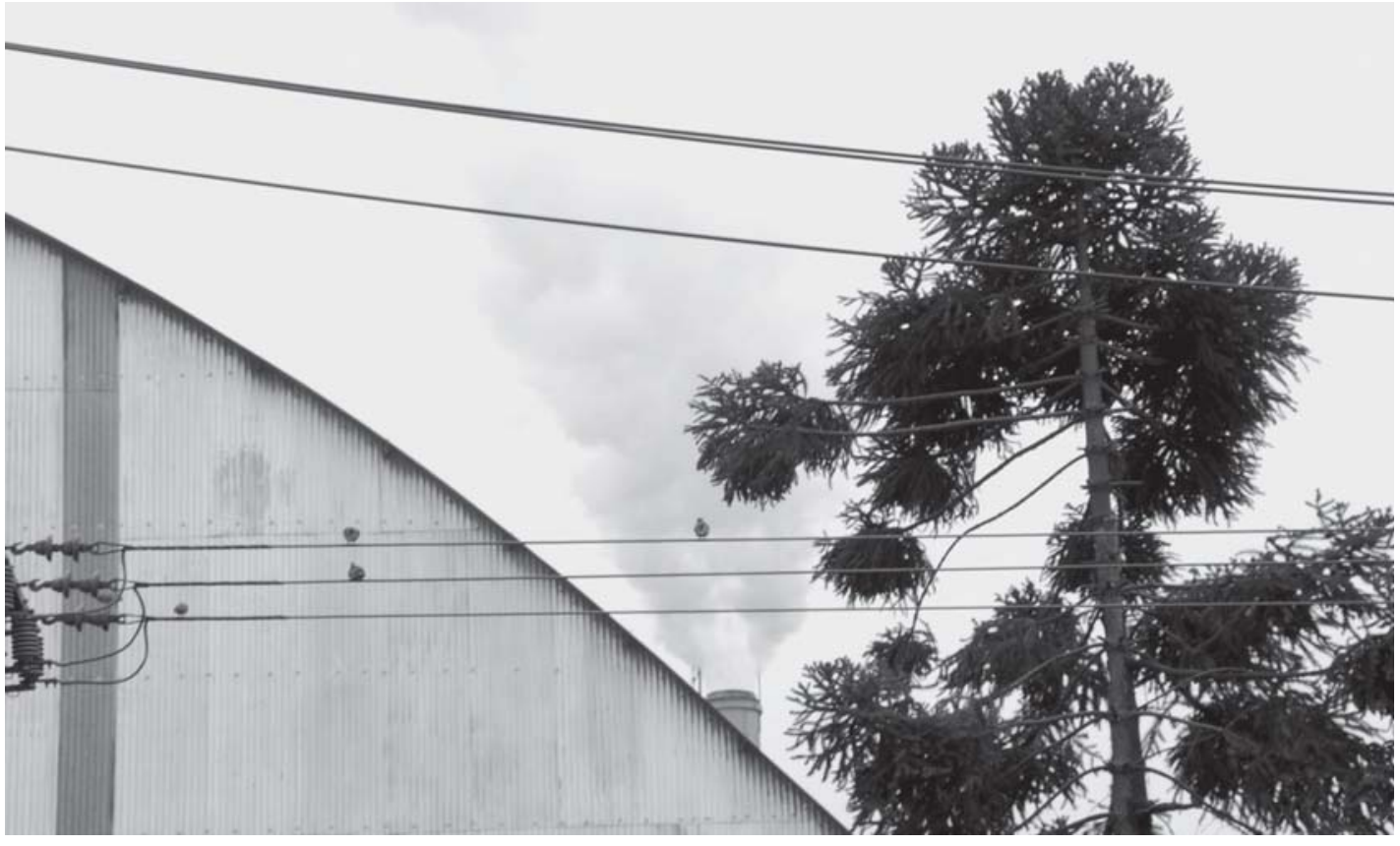

1134 (อ) Interface comunicaçã̃o saúde educação v.l6, n.43, p.II3I-4, out./dez. 2012 